\title{
UČENJE NAJDEMO POVSOD! REVIJA NAJ TO ODSLIKAVA! \\ Intervju s prof. dr. Ano Krajnc ob 20-letnici revije Andragoška spoznanja
}

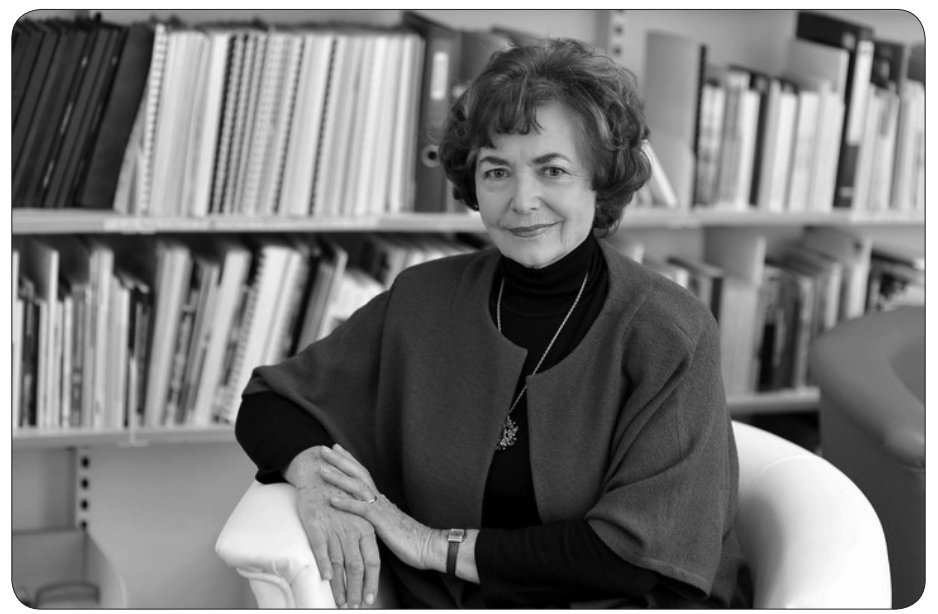

Prof. dr. Ana Kranjc se je na Oddelku za pedagogiko Filozofske fakultete zaposlila po dveh prejšnjih službah, na Zavodu za zaposlovanje in na Inštitutu za sociologijo, kjer je delala kot raziskovalka. Danes se ta oddelek imenuje Oddelek za pedagogiko in andragogiko. V zadnjih 40 letih je bila prehojena dolga pot in mlajši si kar težko predstavljamo, kaj vse je bilo potrebno, da smo danes tu, kjer smo. Nov študij, mnogo knjig, ustanovitev Univerze za tretje življenjsko obdobje, mednarodno sodelovanje ... Med njene uspehe štejemo tudi ustanovitev revije Andragoška spoznanja, ki je temeljna revija za andragogiko in izobraževanje odraslih v Sloveniji. 


\section{Kako se vi spominjate začetkov revije: od prve ideje, da bi revijo sploh vzpostavili, do trenutka, ko ste imeli v rokah prvi tiskani izvod?}

Revija ni nastala kar tako, z danes na jutri; z idejo o reviji sem se ukvarjala vsaj 20 let, preden je začela izhajati. Nove stvari nastajajo, so zanimive, nas privlačijo, ampak zahtevajo tudi vztrajnost in potrpljenje. V 70. letih, ko sem bila po doktoratu na specializaciji na univerzi v Torontu in potem v Ženevi ter nekaj časa v Oxfordu, sem začela razmišljati o razliki med informacijo in znanjem. Trčila sem na izkustveno izobraževanje ljudi, ki veliko vedo, pa niso šolani. Te stvari so me zelo okupirale. V Torontu sem odkrila avtorja Allena Tougha, ki je takrat izdal knjigo Učni projekti odraslih, kjer je ugotavljal, kako je učenje osebna zadeva. V Jugoslaviji smo se takrat še intenzivno ukvarjali z raziskovanjem organiziranega izobraževanja: na to smo gledali skozi število tečajev, število delavskih univerz, število predavateljev, število obiskovalcev. Tam pa sem našla drugo realnost, ki je bila po mojem mnenju nekaj korakov pred nami. In prav ob tem, kako se informacija spreminja v znanje, kako se strukturira, kaj pomeni ta proces, sem videla, da tudi znanstvena spoznanja ne nastanejo kar naenkrat in ne dozorijo $\mathrm{v}$ hipu v celovito knjigo.

Zaslutila sem, kako pomembno je za nas, če hočemo razviti področje izobraževanja odraslih, andragogiko, da ima stroka možnost, da objavlja tudi v obliki krajših člankov, fragmentarne stvari, ki pa so pomembne. To je zelo pomembna vloga revije. Druga vloga pa je, da vzdržuje stik med prakso in znanostjo. Danes bi temu rekli, da mrežimo znanje na različnih ravneh. Moji poskusi od prvega zavedanja, kako pomembno je, da imamo revijo, pa do resnične revije so šli skozi razna obdobja. Zelo tesno sem sodelovala s Sodobno pedagogiko. Z urednikom prof. dr. Vladom Schmidtom sem bila v uredniškem odboru in sem se pri takratnem ministrstvu bojevala, da bi financirali revijo, tako da bi Sodobna pedagogika izhajala $\mathrm{v}$ večjem obsegu in bi bila polovica namenjena izobraževanju odraslih. Nekaj časa so članki o izobraževanju odraslih res izhajali v Sodobni pedagogiki, vendar je ta revija namenjena šolam in šolskim problemom. V tistem času so bili po vseh podjetjih izobraževalni centri brez svojega glasila, ni še bilo interneta, zato je bila potreba po samostojni reviji vse bolj živa.

Tako je počasi nastajala zamisel za revijo. Konec 80. let sem bila na Dunaju pri Združenih narodih, kjer sem imela več stikov z Mednarodnim inštitutom Zveze ljudskih univerz Zahodne Nemčije. Direktor je bil gospod Jakob Horn. Mednarodni inštitut je po padcu berlinskega zidu v različnih državah pomagal pri spodbujanju izobraževanja odraslih. Spominjam se nekega dogodka. Z gospodom Hornom sva letela s Šrilanke proti Zürichu in sva stoje v letalu razpravljala, kako bi lahko pomagali tudi Sloveniji. Tako je Slovenija leta 1994 dobila prva sredstva, da zasnuje revijo. Leta 1995 smo jo ustanovili in začel je izhajati prvi letnik. Mislim, da je bil to velik uspeh. Prišla je ta »injekcija« od zunaj, potem pa smo sami skrbeli za revijo, ki je na leto imela približno 400 strani. To je bil velik zalogaj. Pridobiti smo morali avtorje, bralce in vse drugo ... 


\section{Skoraj vseh 20 let ste bili tudi urednica revije. Kako ste vzdrževali ravnotežje med znanstvenimi in strokovnimi besedili?}

Moram poudariti, da revije ne more ustvariti en človek. Revijo ustvarjajo ekipe. Jaz sem mogoče lahko bila neke vrste vžigalica. Ampak tu je kolegica dr. Dušana Findeisen, potem je dr. Danijela Brečko, ki je bila odgovorna urednica veliko let, nato ji je sledila Tanja Šulak, najprej kot tajnica, potem kot odgovorna urednica, dr. Sonja Kump, ki je vedno priskočila na pomoč. Veliko je bilo sodelavcev, ki so pomagali.

Revija je bila od samega začetka zasnovana kot znanstveno-strokovna. Zavedali smo se, da nismo v Angliji, kjer imajo Studies in the Education of Adults kot izključno znanstveno revijo pa Lifelong Learning, ki je široka in povezana tudi s prakso. Mislim, da si Slovenija glede na število strokovnjakov, ki bi jih zanimala le znanstvena dela iz andragogike, težko privošči zgolj znanstveno revijo. To je bil en argument za to, da bo revija nekako »dvokrilna«, da bo poročala iz prakse in bo imela znanstveni del. To ravnotežje smo poskušali ohraniti.

Zdaj pa izkušnje: ko smo predavali po različnih krajih in smo opazili zanimive primere, smo ljudi animirali, naj kaj napišejo o svojem delu. Znanstveni članki so nastajali na podlagi raziskav na Filozofski fakulteti, na Fakulteti za družbene vede, na Andragoškem centru Slovenije, Pedagoški fakulteti v Ljubljani in Mariboru. Lažje so bili dosegljivi znanstveni članki, ker so avtorji izhajali iz svojih raziskav. Z opisovanjem prakse je bilo težje. Trčili smo ob pretirano skromnost Slovencev. Ljudje so bili prepričani, da pišejo samo »geniji «, »doktorji«. Vsak se je začudil, ko smo ga povabili. Zelo težko je premagati občutek, da »navadni ljudje« ne pišejo člankov. In mislim, da je prav to krivo, da smo zelo težko pridobivali članke iz prakse. Vendar se tudi to spreminja. Naj povem drugačen primer. Pred dvema letoma smo šli z Univerzo za tretje življenjsko obdobje na obisk v Budanje, manjšo vas na Primorskem, kjer je 20 pesnikov skupaj objavilo svoje pesmi v knjigi. Zamislite si vasico, majhno naselje, ki je bilo v preteklosti povsem ruralno. Danes ljudje počnejo še marsikaj. Imeti ambicijo, da si rečeš, jaz bom pesnik, to pomeni, da se tudi odnos do pisanja spreminja, in to je velik korak naprej.

To, da sem združevala prakso in teorijo, je bil delno tudi rezultat mojega študija futurologije. Iz futurologije razberete, kaj se dogaja v informacijski družbi. Praksa in teorija se združita (participatorne raziskave). V industrijski družbi je vladala socialna piramida, skupini intelektualcev in fizičnih delavcev sta bili ločeni. Družba pa je danes kot vrtinec. Nese nas ven, nese nas noter; če izberemo pravo pot, nas ponese v središče. Pomanjkanje kompetenc človeka hitro izvrže spet na rob.

Teorija ne more biti več teorija, če ni združena s prakso; če ni taka teorija, da jo praksa potrjuje. Zato sem vztrajala, da je revija tako praktična kot znanstvena.

Mislim, da ne more nihče drug tako širiti znanosti v prakso kot nekdo, ki se s tem znanstveno ukvarja. Iz znanosti objavlja stvari in jih približa praksi; gre za hiter pretok znanja. Zato je pomembno poznavanje ljudi v njihovem okolju. Mora se zaslutiti, mora se zagledati, kaj ljudje potrebujejo. Če bi razvijali samo znanstveno revijo, bi šli korak nazaj ali pa bi ostali pri stari, izumrli delitvi teorije in prakse. 
Dotakniva se še malo jezika. Revija izhaja v slovenskem jeziku, ki ima razmeroma majhno število uporabnikov. Danes je angleščina univerzalno orodje sporazumevanja. Kako vam je uspevalo ohranjati revijo v tem jezikovnem krogu? Kakšen je pomen tega za razvoj strokovne terminologije in kakšen pomen pripisujete objavam $v$ slovenščini v globaliziranem svetu?

Menim, da zelo velik. Globalizacijo podpiram, ampak globalizacija pomeni tudi lokalni razvoj, pomeni razvoj Slovenije. Posameznik se lahko staplja z drugimi, kot govori tudi transakcijska analiza, če je razvit. Če je človek razvit, če ga ni strah, da se bo v odnosu z drugim izgubil, ko si bosta preblizu, potem se oba razvijata. Po drugi strani pa drži, da se človek razvija le ob človeku. Podobno je pri naciji. Mi se bomo izgubili v drugem, če ne bomo sami dovolj razviti. Moramo se zelo previdno povezovati in odpirati navzven; vedno pod pogojem, da smo sami razviti. Če to prenesem na revijo: podrobnosti našega okolja in izobraževanja ne more predstaviti druga revija. Upoštevanje razmer, zgodovine, kulture, tradicije, vsega, kar nas obdaja in kar smo razvijali, tega izročila kulturnega in naravnega ne more reflektirati nobena tuja revija, ki bi izhajala $v$ angleščini globalno za ves svet. Pogoj za globalne revije je, da so razvite nacionalne revije.

Mi smo lahko revijo ponudili marsikomu, ker so imeli ljudje vtis, da izdajamo revijo, pri kateri vemo, kaj in kako govorimo. To pa je težje narediti v tujem jeziku. Nimam nič proti angleščini. Jaz bi priporočila, da ljudje berejo svojo revijo in sebe vidijo v svojem jeziku in da spoznajo druge prek tujih revij in tujih jezikov.

Poleg slovenskih pa smo imeli že od začetka tudi angleške prispevke. V zadnjih letih je v vsaki številki objavljen članek v angleščini, ker to zahtevajo mednarodne klasifikacije. Gotovo to reviji razširi zaledje.

\section{Tudi finančno je bilo revijo težko vzdrževati. Kako ste pridobivali sredstva zanjo?}

Na tem področju je treba delovati stalno. Mi smo dobili vsako leto nekaj virov od ministrstva za šolstvo in ministrstva za znanost, vendar to ni zadostovalo za štiri številke. Deloma se je revija financirala iz naročnine, deloma pa iz sponzorskih sredstev.

\section{Kakšen položaj je po vaši oceni imela revija v strokovni javnosti in med raziskovalci $\mathbf{v}$ prvih letih izhajanja in kakšnega ima danes?}

To je bilo približno tako, kot je gospod Bučar rekel za Slovenijo. Mi smo bili zelo navdušeni. Vsi smo hoteli imeti svojo državo in takrat se nismo spraševali, ali imamo politike, ki bodo to državo vodili. Podobno je bilo pri reviji. Treba je bilo začeti z vsem: revijo je bilo treba družbeno umestiti, jo predstavljati na raznih konferencah doma in v tujini, študentom, na ljudskih univerzah in v drugih izobraževalnih središčih. Skratka, to je proces, ko gradiš povezave $\mathrm{z}$ bralci in avtorji, ustvarjaš socialni kapital revije. Mi smo vedno poudarjali, da smo odprti, da je dobrodošel vsak avtor, ki je naletel na nekaj, 
o čemer bi rad pisal in je za ljudi pomembno. Se pravi, da smo vabili in tudi »gradili« mrežo avtorjev.

O izobraževanju odraslih je treba pisati z različnih zornih kotov in zajemati z različnih področij. Izobraževanje odraslih je zelo labilna stvar in to najbolje vidite, ko se menjajo vlade ali v krizah. Najlažje je krčiti sredstva za izobraževanje odraslih. Trudili smo se, da smo bili odprti za različne poglede. Število naročnikov se je sicer spreminjalo, a mislim, da neko število bralcev in bralk ostaja stabilno. V teh letih smo se poskušali bralcem približati na različne načine. Nekaj let smo objavljali tudi karikature o izobraževanju. Karikaturistka je narisala vseživljenjsko učenje ali pa izkustveno izobraževanje. Število bralcev se je povečalo, ker se vedno bolj »utapljamo« v likovno izražanje.

\section{Na kateri dosežek v zvezi z izhajanjem revije ste najbolj ponosni?}

Že čisto na začetku sem bila na neki dogodek zelo ponosna. Uredniki revij, ki so nastajale v mednarodnem projektu, ki sem ga prej omenila (koordinator je bila Finska), smo imeli srečanje v Helsinkih. Na tem srečanju je bila naša revija ocenjena kot najboljša, še posebej so poudarili oblikovanje revije. Likovno podobo je takrat izdelal oblikovalec Jure Apih. Zdelo se mi je zelo pomembno, da je revija tudi lepo oblikovana, zato sem bila na to priznanje ponosna. Likovna podoba je del sporočila in takrat smo se trudili, da je bilo dovolj prostora, da je revija »dihala«, da je imela dvobarvni tisk.

Drugo, na kar sem ponosna, pa je povezano z dogodkom, ko sem se čez nekaj let srečala s kolegom iz Estonije, ki je sočasno, v 90. letih prejšnjega stoletja, vodil nastajanje njihove revije. Njihova publikacija je izhajala le poldrugo leto. Ko ni bilo več financiranja iz mednarodnega projekta, je zamrla. Zaradi tega se mi zdi, da je teh 20 let izhajanja res velik uspeh. Uspeh je to, da smo našli pravo pot.

\section{Po 20 letih vašega vodenja revije je uredništvo prevzela nova ekipa. Kaj bi jim sveto- vali na podlagi svojih bogatih izkušenj? Kaj je vaše sporočilo?}

Ne maram dajati nasvetov. Če me kaj vprašajo, jim povem, saj smo skupaj v uredniškem odboru. Vsak urednik ima svoj slog, v delo vlaga svoje poglede, zato naj revijo vodijo, ne da bi jim starejši zapovedovali, prejudicirali, kako naj bo. Poudarila pa bi, da je zdaj prišel čas, ko ne smemo biti skromni in se umikati. Gojiti moramo kakovost revije in biti ambiciozni. Če bi tako na kratko rekla: zmagajo samo tisti najboljši.

Zdajšnje uredništvo deluje v neki drugi družbi, ko ima izbraževanje odraslih drugo vlogo. To je družba raznolikosti. Družba mnogih priložnosti - tudi za odrasle in starejše. Revija mora odsevati to raznolikost in vidim, da novo uredništvo k temu teži. Učenje je danes obarvalo skoraj vse. Najdeš ga povsod in revija bo to vedno bolj odslikavala.

Drugo, kar je pomembno, je povezovanje prakse in teorije. Praksa in teorija gresta z roko v roki, vrhunsko ekspertno znanje se lahko združi s spoznanji iz vsakdanjega življenja. Naj 
omenim samo en kratek primer kustosa za babilonsko kulturo, ki vodi knjižnico na 15 tisoč glinenih ploščicah v Londonu. Neki Londončan mu je prinesel ploščico, ki jo je kupil na bolšjem sejmu, in ga je želel vprašati, ali je to kaj vredno. Strokovnjak je dejal: »Jaz sem vse življenje iskal to ploščico! « To je kustosu dalo misliti, kako je mogoče, da Londončani nič ne vedo o babilonski knjižnici in kulturi. Nič nimajo od te knjižnice. Nato je napisal knjigo o babilonski kulturi na tak način, da so jo razumeli vsi ljudje. Danes je izobrazbena struktura višja. Znanost mora biti takšna, da jo človek razume, ne samo strokovnjak z nekega področja. Ko je strokovnjak za babilonsko kulturo napisal knjigo, je rekel: »Vem, da je to glas novega časa: združevati teorijo in prakso.« To vidim kot pomembno tudi za revijo.

Tretje vprašanje je: tiskana revija in internet. Če nisi na internetu, na tem svetu ne obstajaš. Mislim, da je zato tudi pomembno, da izhajata tiskana oblika in e-revija. Lahko se tudi razlikujeta, da se vidi, kaj se ponudi v eni in kaj v drugi obliki. Smo ljudje, ki imamo radi še revijo na papirju in jo radi vidimo napisano, in so ljudje, ki berejo le posamezne članke v e-obliki.

\section{Če se odmakneva od revije, kaj napovedujete za prihodnost izobraževanja odraslih?} Kako na to vpliva tehnološka revolucija, ki ste jo omenili, in kako bo vplivala v prihodnje?

Te trende že vidimo. Gotovo bo mreža ustanov za izobraževanje odraslih ostala. Posamezniki nimamo časa, če se moramo nekaj naučiti, da bi vedno sami začeli brskati po neki znanosti od začetka. Internet pomaga, ampak včasih je potrebno neko znanje, da sploh izbereš iz ponudbe. Zato potrebuješ mentorja. »Naučiti se učiti « je ena od štirih temeljnih spretnosti, ki se zahtevajo od današnjega človeka. To pomeni, da zna sam voditi svoje učenje. Veliko ljudi tega še ne zmore in potrebuje andragoške ustanove. Vedno bolj poudarjamo osebnostni razvoj in na tem področju se bodo razvile nove oblike izobraževanja.

Pogosto slišimo za hitre nasvete, kako postati samozavestni, boljši. Vendar se osebnostni razvoj zgodi le z drugo osebo. Predvidevamo lahko, da bo izobraževanje odraslih preplavilo veliko individualiziranih oblik izobraževanja in svetovanja. »Ljudje se učijo, da postajajo, obstajajo in pripadajo, « je dejal R. Kidd. Kako kompleksno postaja izobraževanje odraslih! Učenje ima široko postavljene cilje, ki se uresničujejo v vsakem posamezniku drugače. Posameznik pa potrebuje drugega posameznika, da se uresničuje, da osebnostno raste. Krepi se pomen mentorske vloge, toda ne more biti vsak pravi mentor. Pravi mentor je le glede na odnos z mentoriranim. V tem smislu individualizacije in osebnostne rasti vidim prihodnost. Življenje je vseživljenjsko izobraževanje, kajne?

\section{Zahvaljujem se vam za vaš čas in vaše misli. Reviji pa skupaj zaželiva še veliko dese- tletij uspešnega izhajanja.}

Ja, tiskano in v e-obliki. 